\title{
Forecasting Euro Area Real GDP: Optimal Pooling of Information
}

\author{
OLIVER HÜLSEWIG \\ JOHANNES MAYR \\ TIMO WOLLMERSHÄUSER
}

CESIFO WORKING PAPER NO. 2371

CATEgORY 6: MONETARY POLICY AND InTERnAtIONAL FINANCE August 2008

\footnotetext{
An electronic version of the paper may be downloaded

- from the SSRN website: www.SSRN.com

- from the RePEc website: www.RePEc.org

- from the CESifo website: www.CESifo-group.org/wp
} 


\title{
Forecasting Euro Area Real GDP: Optimal Pooling of Information
}

\begin{abstract}
This paper proposes a new method of forecasting euro area quarterly real GDP that uses areawide indicators, which are derived by optimally pooling the information contained in national indicator series. Following the ideas of predictive modeling, we construct the area-wide indicators by utilizing weights that minimize the variance of the out-of-sample forecast errors of the area-wide target variable. In an out-of-sample forecast experiment we find that our optimal pooling of information approach outperforms alternative forecasting methods in terms of forecast accuracy.

JEL Code: C13, C51, C53, C82, E37.
\end{abstract}

Keywords: forecasting, aggregation, model averaging, real time experiment.

Oliver Hülsewig

Ifo Institute for Economic Research at the

University of Munich

Poschingerstrasse 5

81679 Munich

Germany

Huelsewig@ifo.de
Johannes Mayr

Ifo Institute for Economic Research at the

University of Munich

Poschingerstrasse 5

81679 Munich

Germany

Mayr@ifo.de

Timo Wollmershäuser

Ifo Institute for Economic Research at the University of Munich

Poschingerstrasse 5

81679 Munich

Germany

Wollmershaeuser@ifo.de

July 23, 2008

We are grateful to Mardi Dungey, Domenico Giannone, Denise Osborn and Antonio Espasa for very helpful comments and suggestions. In addition we benefitted from the reactions of the participants of the workshop Using Euro Area Data: Issues and Consequences for Economic Analysis by the CEPR, the EABCN and the Centre for Financial Analysis \& Policy held in Cambridge, March 2008, the Canadian Economic Society Annual Conference, Vancouver, June 2008, the Australasian Meeting of the Econometric Society in Wellington, New Zealand, July 2008 and the Austrian Economic Society Conference in Vienna, May 2008. The usual disclaimer applies. 


\section{Introduction}

Since Eurostat publishes the first official release of euro area quarterly real GDP several weeks after the end of each quarter, an early assessment of the actual state of the economy is appreciable. Timely information is contained in business cycle indicators - e.g. industrial production, confidence surveys or composite indicators - that are more promptly available. Forecasts of euro area quarterly real GDP are frequently derived by means of bridge models that explicitly incorporate such business cycle indicators.

In the euro area, business cycle indicators are typically collected at a national level by national statistical agencies or national survey institutes. In such a data-rich environment professional forecasters who aim at predicting euro area quarterly real GDP, can choose between two forecast strategies: pooling of forecasts and pooling of information (Diebold and Lopez, 1996). Pooling of forecasts uses national indicator series as predictors in the bridge model equations. One strategy is to generate a number of forecasts of euro area real GDP growth rates by employing various parsimonious models and to combine them to a single forecast of the area-wide target variable. The optimal weighting scheme thereby takes the correlations of the forecast errors of each model into account (Bates and Granger, 1969). Alternatively, real GDP growth rates of each euro area member country can be forecasted separately and then be aggregated to a single euro area real GDP growth rate by using the relative economic weight of each member country (Marcellino, Stock, and Watson, 2003).

Pooling of information generates a projection of euro area real GDP growth rates by using area-wide indicators as predictors that combine the information of the national indicators. Thus, the number of regressions is reduced to one. The simplest strategy is to employ the area-wide indicators which are provided by Eurostat or other institutions - e.g. the European Commission or the OECD - and which are economically weighted averages of national indicators. Alternatively, professional forecasters might combine the set of national information by extracting common dynamic factors or principal components (Forni, Hallin, Lippi, and Reichlin, 2000, and Stock and Watson 2002).

This paper proposes a new method of forecasting euro area quarterly real 
GDP that uses area-wide indicators, which are derived by optimally pooling the information contained in national indicator series. Following the ideas of predictive modeling, we construct the area-wide indicators by utilizing weights that minimize the variance of the out-of-sample forecast errors of the aggregate target variable. By allowing a pre-aggregation of individual information to national indicator series, the optimal pooling of information problem is reduced to a manageable number of variables, which avoids the construction of a "super model" (Timmermann, 2005) whose computation is often deemed to be prohibitively costly or even impossible.

To evaluate the forecast performance of our optimal pooling of information approach, we focus on three euro area business cycle indicators, which are all available at both the area-wide and the national level: the Industrial Production Index (IPI), the Economic Sentiment Indicator (ESI) of the European Commission and the CESifo World Economic Survey (WES) indicator for the euro area. The forecast models are specified as Autoregressive Distributed Lag (ADL) models, which are estimated by employing a model averaging strategy in order to reduce the problems associated with selecting a certain lag length. In a first step, we evaluate the potential gain of the optimal pooling of information approach in a forecast exercise using ex ante information. Our main result is that optimally pooled area-wide indicators significantly reduce the out-of-sample mean squared forecast errors (MSE) for euro area quarterly real GDP growth by $40 \%$ on average compared to economically weighted indicators. An analysis of the optimal weighting schemes shows that only a limited number of national indicators is attributed a weight larger than zero. Furthermore, we find that the optimal weights derived from shorter optimization windows are almost identical to those derived from the entire out-of-sample window. These results indicate a certain stability of the optimal weights and support the application of our approach in practice.

In a second step, we evaluate the applicability of the optimal pooling of information approach in real-time by employing a pseudo out-of-sample forecast experiment, in which optimally pooled area-wide indicators are computed using only ex-post information that would have been available in real-time. The optimized weights are derived from a recursively growing optimization window, which is then excluded from the forecast evaluation process. The performance of 
the optimal pooling of information approach is compared to a number of alternative forecast methods, which include pooling of forecast strategies and competing pooling of information strategies. We find that our optimal pooling of information approach generally outperforms the alternative forecast methods in terms of forecast accuracy as measured by the out-of-sample forecast MSE.

The remainder of the paper is structured as follows. Section 2 reviews the traditional forecast strategies. In Section 3 we introduce the optimal pooling of information approach. In Section 4 we present our forecast experiment. We describe the forecast models applied, introduce the data set and discuss the empirical results, which refer to (i) the use of ex-ante information and (ii) to the use of ex-post information. Section 5 summarizes and concludes.

\section{Review of Traditional Forecast Strategies}

For an overview of the traditional forecast strategies we introduce the following notations. Suppose we forecast the aggregate target variable $Y_{t}$ - i.e. euro area quarterly real GDP growth - using a broad set of disaggregate information variables, denoted by $X_{i, t}$, where $t$ is time and $i$ refers to the disaggregate unit, i.e. the member states of the currency area. The number of disaggregate units is given by $K$. The data sample that is available for the forecast experiment ranges from $t=1, \ldots, \Theta_{2}$. The forecast model is estimated recursively over the estimation window $[1, T]$, with $T$ gradually increasing from $\Theta_{0}$ to $\Theta_{2}-1$, where $1<\Theta_{0}<\Theta_{2}-1$.

The one-step-ahead out-of-sample forecasts of the area-wide target variable, denoted by $\widehat{Y}_{T+1 \mid T+1}$, are computed for $T+1$ using the national information already available at $T+1 .^{1}$ As $T$ increases from $\Theta_{0}$ to $\Theta_{2}-1$, the number of out-of-sample forecasts is given by $\Theta_{2}-\Theta_{0}$. The performance of the different forecast strategies is evaluated by computing the MSE for each model over the forecast evaluation window $\left[\Theta_{0}+1, \Theta_{2}\right]$ on the basis of the out-of-sample forecast errors $\widehat{\varepsilon}_{T+1 \mid T+1}=Y_{T+1}-\widehat{Y}_{T+1 \mid T+1}$. Figure 1 summarizes the time structure of the estimation and forecast evaluation windows.

\footnotetext{
${ }^{1}$ Since in our set-up the current quarter is estimated, the literature often uses the notion "nowcast" instead of forecast (Domenico, Reichlin, and Small (2006)).
} 


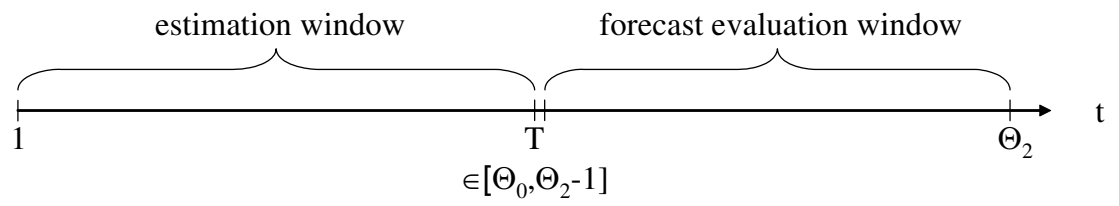

Figure 1: Time structure of the estimation and forecasting procedures

Notice that in the following we use a static structure of the forecasting models to keep the review as simple as possible. Later in the empirical part of the paper, we allow for more dynamics.

\subsection{Pooling of Forecasts}

Pooling of forecasts summarizes the combination of two or more individual forecasts to generate one single, pooled forecast. The idea of improving the accuracy of predictions regarding a certain target variable by combining the forecasts of different models was first proposed by Bates and Granger (1969) and mainly follows the ideas of portfolio optimization and diversification gains. A large number of theoretical and empirical studies - see e.g. Timmermann (2005) and Stock and Watson (2004) - have shown the superiority of combined model based predictions.

In the context of forecasting euro area quarterly real GDP, three strategies have been proposed for combining single forecasts, which are derived from national indicator series using a multiple equation set-up. The crucial issue in all strategies is the determination of an adequate weighting scheme.

\subsubsection{Optimal Combination of Area-Wide GDP Forecasts}

In the first strategy the following forecasting model is estimated for each of the $K$ national indicators over the period $t=1, \ldots, T$ :

$$
Y_{t}=\delta+c_{i} X_{i, t}+\varepsilon_{i, t},
$$

where $\delta$ is a constant term, $c_{i}$ denote parameter matrices and $\varepsilon_{i, t}$ are error terms. The $K$ forecasts resulting from the models are then linearly combined to a single 
forecast for the area-wide target variable according to:

$$
\widehat{Y}_{T+1 \mid T+1}=\sum_{i=1}^{K} \omega_{i} \widehat{Y}_{T+1 \mid T+1}^{i},
$$

where the superscript $i$ attached to $\widehat{Y}_{T+1 \mid T+1}$ denotes the forecast of the area-wide target variable obtained from the model using the national indicator $X_{i, t}$.

The optimal weights $\omega_{i}$ of the single forecasts, and hence the weights attributed to each model, depend on the model's out-of-sample performance. Under the assumption that the forecasts are unconditionally unbiased, the $\Theta_{2}-\Theta_{0}$ out-of-sample forecast errors of model $i, \widehat{\varepsilon}_{T+1 \mid T+1}^{i}=Y_{T+1}-\widehat{Y}_{T+1 \mid T+1}^{i}$ with $T=$ $\Theta_{0}, \ldots, \Theta_{2}-1$, are normally distributed around zero with variance $\sigma_{i}^{2}$ and covariance $\rho_{i j} \sigma_{i} \sigma_{j}$ for $j=1, \ldots, K$, where $\rho_{i j}$ denotes the correlation coefficient of the forecast errors from the forecast models $i$ and $j$. Defining $\boldsymbol{\omega}$ as the $K \times 1$ vector containing the weights of each model and $\boldsymbol{\Sigma}_{\widehat{\varepsilon}}$ as the $K \times K$ variance-covariance matrix of the out-of-sample forecast errors, the optimal weights are obtained from minimizing the variance of the combined out-of-sample forecast error:

$$
\boldsymbol{\omega}^{o p t}=\arg \min _{\omega}\left[\boldsymbol{\omega}^{\prime} \boldsymbol{\Sigma}_{\widehat{\varepsilon}} \boldsymbol{\omega}\right]
$$

which gives:

$$
\boldsymbol{\omega}^{o p t}=\frac{\boldsymbol{\Sigma}_{\widehat{\varepsilon}}^{-1} \mathbf{1}_{N}}{\mathbf{1}_{N}^{\prime} \boldsymbol{\Sigma}_{\widehat{\varepsilon}}^{-1} \mathbf{1}_{N}} .
$$

A major benefit of the combination of forecasts approach is the possibility of including a large number of candidate regressors in forecasting a certain target series without of running into the problem of overparametrization or overfitting. However, as the data generating process is typically unknown, the need to specify a large number of parsimonious regression models may lead to high specification errors (Lütkepohl, 1987). The major challenge of the approach is the estimation of the variance-covariance matrix $\boldsymbol{\Sigma}_{\widehat{\varepsilon}}$. Assuming linear relationships, the optimal weights can be estimated by ordinary least squares, regressing realizations of the target variable $Y_{t}$ on the $\mathrm{K}$-vector of forecasts $\widehat{Y}_{T+1 \mid T+1}^{i}$ and the constant term (Granger and Ramanathan, 1984). However, for the computation of the optimal weights problems arise if the number of models $K$ is too large. 


\subsubsection{Equally Weighted Combination of Area-Wide GDP Forecasts}

A simplification of the optimal combination approach is the use of equal weights, which particularly solves the computation problem. Concerning the forecast performance of equally weighted combinations, Timmermann (2005) derives conditions, under which the simple average of a number of forecasts outperforms single model based forecasts as well as more elaborated weighting schemes. Among others, Stock and Watson (2004) provide evidence for the superiority of the equal weighting scheme in a broad empirical application, thereby confirming the socalled forecast combination puzzle.

\subsubsection{Aggregation of National GDP Forecasts}

Following Marcellino, Stock, and Watson (2003) the third strategy is to aggregate national real GDP forecasts to a single euro area real GDP forecast. The forecast model is estimated for each member country of the monetary union $i=1, \ldots, K$ over the period $t=1, \ldots, T$ :

$$
Y_{i, t}=\delta_{i}+c_{i} X_{i, t}+\varepsilon_{i, t}
$$

and forecasts of euro area real GDP growth are generated by computing weighted averages of the national predictions:

$$
\widehat{Y}_{T+1 \mid T+1}=\sum_{i=1}^{K} \omega_{i} \widehat{Y}_{i, T+1 \mid T+1}=\sum_{i=1}^{K} \omega_{i} \widehat{\delta}_{i}+\sum_{i=1}^{K} \omega_{i} \widehat{c}_{i} X_{i, T+1}
$$

The economic weights $\omega_{i}$ reflect the relative importance of country $i$ in the monetary union (e.g. GDP shares).

In contrast to the optimal combination approach, the weighting of national information $X_{i, t}$ is not derived from the minimization of the variance of the outof-sample forecast error, but is influenced by both, the in-sample fit of the disaggregate model for country $i$ and the economic weight of country $i$ (see equation (6)). As before, the approach hardly suffers from the problem of overfitting. However, due to the need to specify of a large number of parsimonious models, it faces the drawback of larger specification errors when the data generating processes are unknown. 


\subsection{Pooling of Information}

Pooling of information generates a projection of euro area quarterly real GDP by using area-wide indicators as predictors that combine all national information. In contrast to the multi-equation approaches of forecast pooling, pooling of information reduces the number of regressions to one and - as a consequence - the problem of running into specification errors is reduced. The crucial issue of the pooling of information approach is again the weighting scheme applied to derive area-wide indicators from the national indicator series.

\subsubsection{Economic Weights}

A straightforward strategy is to use area-wide indicators officially provided by statistical agencies as regressors of the forecasting model:

$$
Y_{t}=\delta+c X_{t}+\varepsilon_{t}
$$

where $t=1, \ldots, T$. The area-wide indicator $X_{t}$ is computed as a weighted average of national indicators:

$$
X_{t}=\sum_{i=1}^{K} \omega_{i} X_{i, t},
$$

where the $\omega_{i}$ 's typically reflect country $i$ 's relative economic weight in the currency area.

Employing economic weights to construct a single aggregate indicator series implies that these weights are exogenously given. Thus, any correlation between the national indicator series is ignored. Furthermore, the approach does not take any correlations between the resulting indicator series and the area-wide target variable into account.

\subsubsection{OLS Weights}

The use of OLS weights circumvents this drawback. Estimating the forecast model:

$$
Y_{t}=\delta+\sum_{i=1}^{K} c_{i} X_{i, t}+\varepsilon_{t}
$$


over the period $t=1, \ldots, T$, the weighting of national information is given by the point estimates for $c_{i}$, which are derived from the minimization of the in-sample residuals. Thus, the in-sample fit of this approach with respect to the aggregate target variable must be superior to a multiple equation approach (see Section 2.1.3). The problem of this approach is, however, that with an increasing number of disaggregate information variables $K$, the regression model more likely suffers from overfitting. As overparametrization leads to higher estimation uncertainty in finite samples, the out-of-sample performance of the OLS weighting approach is likely to worsen.

\subsubsection{Factor Models}

The use of factor models attempts to mitigate the problem of parameter proliferation. While the forecasting model has the same structure as in equation (7), it is preceded by a factor model that pools disaggregate information over the estimation window $[1, T]$ to a common factor $X_{t}$, which is used to forecast the target variable $Y_{t}$.

The intuition behind factor models in the context of macroeconomic forecasting is that the co-movement in economic time series, in our case the co-movement in the national indicator series, is arising largely from a small set of common factors or even from a single common factor. A number of estimation techniques have been applied in the literature. The simplest method of constructing latent factors proposed by Stock and Watson (2002) is the static principal components analysis (PCA). In our case, the single common factor thereby corresponds to the first principal component, which accounts for as much of the variability in the disaggregate indicators as possible. The weights $\omega_{i}$ are the squared elements of the eigenvector, which is associated with the first principal component. If the resulting common factor explains a large part of the variance of $X_{i, t}$, then $X_{i, t}$ is attributed a high weight.

In the context of business cycle analysis a useful extension of the static version of the factor model is the generalized dynamic factor model of Forni, Hallin, Lippi, and Reichlin (2000), which takes into account phase differences between disaggregate indicator time series by appropriately weighting leading and lagging 
variables. Kapetanios and Marcellino (2006) propose a state-space model as an alternative and flexible technique to estimate the dynamic common factors. The advantage of factor models is that information of a possibly large set of indicators is pooled by taking into account the in-sample covariances between the candidate regressors. The main drawback of the factor model is that the construction of the common factor ignores any correlation between the common factor $X_{t}$ and the area-wide target variable $Y_{t}$. Thus, the weighting of national information only reflects in-sample correlation patterns between the national indicators and is independent of the forecasting model.

\section{Optimal Pooling of Information}

In the optimal pooling of information approach forecasts of euro area quarterly real GDP are derived from area-wide indicators that are constructed from national indicator series by using optimal weights, which minimize the variance of the out-of-sample forecast errors of the area-wide target variable. The procedure involves a non-linear numerical optimization routine, which accounts for correlations between both, the national indicator series and the area-wide target series.

The determination of the optimal weights includes the following steps. We begin with an initial guess for the weights $\boldsymbol{\omega}=\left(\omega_{1}, \ldots, \omega_{K}\right)^{\prime}$. We then compute the area-wide indicator $X_{t}$ according to equation (8) and estimate equation (7) over the period $t=1, \ldots, T$. Finally, we compute the out-of-sample forecasts:

$$
\widehat{Y}_{T+1 \mid T+1}(\boldsymbol{\omega})=\widehat{\delta}+\widehat{c} \sum_{i=1}^{K} \omega_{i} X_{i, T+1 \mid T+1}=\widehat{\delta}+\widehat{c} \boldsymbol{X}_{T+1 \mid T+1}^{\prime} \boldsymbol{\omega},
$$

where $\boldsymbol{X}_{T+1 \mid T+1}$ is a $K \times 1$ vector containing the national indicators at time $T+1$. The related out-of-sample forecast error is:

$$
\widehat{\varepsilon}_{T+1 \mid T+1}(\boldsymbol{\omega})=Y_{T+1}-\widehat{Y}_{T+1 \mid T+1}(\boldsymbol{\omega}) .
$$

The optimal weights then result from the minimization of the variance of the out-of-sample forecast error:

$$
\boldsymbol{\omega}^{o p t}=\arg \min _{\omega}\left[\left(\widehat{\varepsilon}_{T+1 \mid T+1}(\boldsymbol{\omega})\right)^{2}\right] \text { s.t. } \sum_{i=1}^{K} \omega_{i}=1 .
$$


Following the idea of sparse and stable portfolio optimization - see e.g. Brodie, Daubechies, De Mol, and Giannone (2007) - we regularize our objective function by restricting the weights to be non-negative and to sum up to unity. Introducing theses conditions leads to a stabilization of the optimization problem and promotes sparse portfolios by attributing a weight of zero to a number of national indicators.

The main advantage of the optimal pooling of information approach is that it takes into account correlations between both, predictors as well as predictors and the target variable. In contrast to other pooling of information strategies these correlations refer to the out-of-sample performance of the forecast model. Thus, as a way of predictive modeling optimal pooling of information poses a way to handle the bias-variance trade-off that typically appears when specifying a forecast model. A major drawback of the approach is that with an increasing number of disaggregate information $K$ the computation of optimal weights may become difficult. One way to circumvent the construction of such a "super model" (Timmermann, 2005) is to pre-aggregate individual information to national indicator series, which reduces the optimal pooling of information problem to a manageable number of variables. ${ }^{2}$

\section{Empirical Results}

\subsection{Forecast Model Specification}

Following Banerjee, Marcellino, and Masten (2005), we generate forecasts of euro area quarterly real GDP by using bridge models that are specified as:

$$
A(L) Y_{t}=\delta+B(L) X_{t}+\varepsilon_{t}
$$

where $Y_{t}$ denotes real GDP expressed in quarterly growth rates, $\delta$ is a constant term, $X_{t}$ describes the quarterly values of a business cycle indicator, $A(L)$ and

\footnotetext{
${ }^{2}$ In case of consumer or business surveys, the number of disaggregate information $K$ can be very large as the approach could in principle be tracked down to the level of single survey respondents.
} 
$B(L)$ are lag polynomials and $\varepsilon_{t}$ denotes the error terms. ${ }^{3}$ Quarterly projections of real GDP growth are derived by exploiting the timely information contained in the contemporaneous business cycle indicator in addition to the information provided by past realizations.

An important issue in specifying bridge models for forecasting purposes is the choice of the number of lags of the endogenous and exogenous variables included. Since traditional lag selection approaches - such as in-sample and out-of-sample criteria - suffer from shortcomings, e.g. problems of overparametrization or the use of ex post information that would not have been available in real time, we do not restrict the model specifications to a certain lag length but implement a model averaging strategy that allows us to consider different lag orders. Accordingly, we follow the notion that it is a priori impossible to discard a certain lag order from the forecasting exercise. We derive forecasts from a business cycle indicator within each forecast model by considering a certain maximum number of lags of the exogenous and endogenous variables. The different model specifications are built by permutating the candidate regressors and imposing the restriction that the contemporaneous value of the business-cycle indicator forms part of each model. ${ }^{4}$ One-step-ahead forecasts from every model specification are computed. Since simple pooling schemes perform comparably well (see e.g. Timmermann, 2005, and Stock and Watson, 2004), the forecasts are then combined using equal weights.

\subsection{Data Set}

Our data set includes real GDP and several business cycle indicators. The data is collected for both, the euro area and the member states, over the period from 1990Q1 to 2007Q2. Real GDP from 1995Q1 on is taken from the OECD's Main Economic Indicators Original Release Data and Revisions Database that com-

\footnotetext{
${ }^{3}$ Notice that in cases where national information enters the bridge model equation (13) and/or if national real GDP growth rates are used as dependent variables, the following model specification applies: $A(L) Y_{i, t}=\delta+B(L) X_{i, t}+\varepsilon_{i, t}$.

${ }^{4}$ In the following we specify the forecasting models with a maximum lag length of two, which means that we obtain 16 different model specifications for each business-cycle indicator.
} 
prises vintage data, which is published each month since January $2000 .^{5}$ In order to get a balanced panel of real GDP data, the period from 1990Q1 to 1994Q4 was completed with real GDP data for the member countries from the final vintage of the OECD database and real GDP data for the euro area from the Area Wide Model of the Euro Area Business Cycle Network (EABCN). Real GDP is seasonally adjusted and converted into quarterly growth rates to satisfy stationarity conditions.

For a business cycle indicator to be selected the following criteria had to be met: (1) It is published both at the area-wide and at the national level. (2) It is a leading or a coincident indicator of economic activity and therefore suited to forecast real GDP growth. (3) The indicator is published quarterly or at a higher frequency. (4) It covers a sufficient time span, starting at least in 1990. (5) It is either not revised or vintage data is available covering the total time span. Keeping these guidelines in mind, we end up with three business cycle indicators, namely the Industrial Production Index (IPI), the Economic Sentiment Indicator (ESI) of the European Commission and the CESifo World Economic Survey (WES).

The IPI provides a measure of the volume of value added generated by production units classified under the industrial sectors, i.e. C (mining), D (manufacturing) and E (electricity, gas and water) of the International Standard Industrial Classification of all Economic Activities (ISIC Rev.3). It is released on a monthly basis so that the quarterly value is derived from the monthly average. In the euro area data are collected by the national statistical offices and aggregated by Eurostat to an area-wide index. The country weights used for the aggregation are value added at factor costs; they are revised every five years (Eurostat, 2006). As the indicator is subject to data revisions, vintage data is provided by the OECD's Main Economic Indicators Original Release Data and Revisions Database from 1990 onwards.

The ESI combines the weighted information contained in confidence indicators of different sectors - namely industry, services, construction, retail trade and

\footnotetext{
${ }^{5}$ Since real time data for Ireland, Luxembourg and Greece starts considerably later in the OECD database, we excluded these three countries from our data set. The nine remaining countries cover almost $95 \%$ of area-wide economic activity.
} 
consumers - that are in turn constructed from survey data. Since the indicator is published on a monthly basis, the quarterly value is computed as an average of the monthly releases within the survey quarter. The ESI is built in two steps. In a first step, the area-wide confidence indicators of each sector are derived by aggregating the individual country sector confidence indicators. The weights are the shares of each of the member states in an area-wide reference series - here GDP growth - and are smoothed by calculating a two year moving average. In a second step, the area-wide confidence indicators are combined by using survey weights, which are based on two criteria: (i) the importance of the corresponding sector in the overall economy, and (ii) the ability of tracking the movements of the reference series (European Commission, 2007).

Finally, the WES summarizes the judgement of economic experts about the economic situation of the country they inhabit by revealing their appraisals and expectations. It is exclusively based on qualitative information and is timely released within the survey quarter on a quarterly basis. The WES is collected for each member state of the euro area, whereby the aggregate area-wide index is calculated as a weighted average of the individual country indices. The weighting scheme adopted refers to the share of a single country in total world trade (Stangl, 2007). ${ }^{6}$

\subsection{Forecast Experiment Using Ex-Ante Information}

We generate forecasts of euro area quarterly real GDP by estimating bridge models for each business cycle indicator recursively. We focus on the entire forecast evaluation window that ranges from $\Theta_{0}=1999$ Q4 to $\Theta_{2}=2006 \mathrm{Q} 2$. The projections are derived as nowcasts for every quarter following the end of the estimation window $T$, which is gradually extended from 1999Q3 to 2006Q1.7

Since we seek to evaluate the full forecast potential of the optimal pooling of

\footnotetext{
${ }^{6}$ The calculation of the national trade volumes is based on the foreign trade statistic published by the United Nations. The weighting scheme is readjusted once a year.

${ }^{7}$ Following Zarnowitz and Braun (1992) and Batchelor (2001) we use the release of real GDP, available one year after the end of the respective quarter as the relevant realization for computing the forecast errors. As our data set ranges from 1990Q1 to 2007Q2 the last projection is generated for 2006Q2.
} 
information approach, the computation of the optimal weights draws on the 27 out-of-sample forecast errors of the entire forecast evaluation window. As the forecast evaluation window and the optimization window coincide, we explicitly use so-called ex-ante information to optimize the weights, which means that we use information that would not have been available in real time. ${ }^{8}$ Notwithstanding this analysis allows us to gain an insight into the composition of the weighting schemes that result from the optimization algorithm.

Table 1: Forecast performance of optimally pooled indicators relative to economically weighted indicators

\begin{tabular}{lccc}
\hline \hline & & MSE ratio & HLN p-value \\
\hline Industrial Production & IPI & 0.69 & 0.05 \\
Economic sentiment & ESI & 0.47 & 0.01 \\
CESifo Economic Climate & WES & 0.63 & 0.01 \\
\hline \hline
\end{tabular}

Notes: The MSE ratios are calculated as the MSE resulting from optimally pooled area-wide indicators relative to the MSE resulting from economically weighted area-wide indicators. The HLN p-value was calculated from a Student's $t$-distribution with $\Theta_{2}-\Theta_{0}-1=26$ degrees of freedom.

Analyzing the full forecast potential of optimal pooling of information, the results in Table 1 indicate that forecast accuracy in terms of the out-of-sample MSE calculated over the entire forecast evaluation window is on average improved by around $40 \%$ compared to the economically weighted indicators. The test of forecast accuracy by Harvey, Leybourne, and Newbold (1997) - denoted HLN hereafter - clearly confirms the significance of the improvement. ${ }^{9}$

For an insight into the composition of the optimally pooled area-wide indicators, Table 2 depicts the weights that the optimization algorithm attributes to the single national indicator series. For the IPI almost all national indicators are

\footnotetext{
${ }^{8}$ For a comparison of the forecast performance of different forecast strategies in a real-time experiment, the optimization window should be separated from the evaluation window in order to avoid any informational advantages. We perform such an experiment below (see Section 4.4).

${ }^{9}$ The null hypothesis of the HLN test is that the difference between the squared out-ofsample forecast error resulting from optimally pooled area-wide indicators and the squared out-of-sample forecast error resulting from economically weighted area-wide indicators is not less than zero.
} 
considered - the only exception is the Portuguese indicator - while for the ESI and the WES a smaller number of national indicator series are selected. ${ }^{10}$ In the case of the IPI high weights are attributed to Germany, France, Italy and Spain, which also constitute the largest economies in the currency area. Likewise in the cases of the ESI and the WES a large weight is assigned to Germany, but also to a subset of indicators of smaller countries, such as the Netherlands and Portugal. Surprisingly, for the ESI the Dutch indicator series obtains a weight that lies far above the Dutch share in euro area economic activity, which is currently around $5 \%$. For the WES the same holds for the Portuguese indicator series. Even more surprisingly, despite the eminent economic role of France, Italy and Spain within the euro area, in the cases of both, the ESI and the WES, the indicators of these countries obtain weights which are close to or even equal to zero.

Table 2: Optimal weighting schemes

\begin{tabular}{lccc}
\hline \hline National Indicator Series & IPI & ESI & WES \\
\hline Austria & 0.04 & - & 0.00 \\
Belgium & 0.04 & 0.00 & 0.00 \\
Finland & 0.05 & 0.00 & 0.00 \\
France & 0.19 & 0.01 & 0.00 \\
Germany & 0.17 & 0.69 & 0.52 \\
Italy & 0.35 & 0.00 & 0.00 \\
Netherlands & 0.06 & 0.30 & 0.24 \\
Portugal & 0.00 & 0.00 & 0.19 \\
Spain & 0.10 & 0.00 & 0.04 \\
\hline \hline
\end{tabular}

Notes: The weights are derived by minimizing the out-of-sample MSE resulting from 27 onestep ahead forecasts.

In order to analyze why certain national indicators enter the optimally pooled area-wide indicators, we calculated the out-of-sample MSE resulting from areawide models using only a single national indicator as predictor relative to the MSE resulting from an area-wide model using the economically weighted areawide indicators. The results are shown in Table 3 in which the best-performing national indicators are marked in bold. A comparison of the relative MSEs with

\footnotetext{
${ }^{10}$ Notice that for the ESI information on the Austrian indicator series is not available.
} 
the results reported in Table 2 shows that the optimization algorithm attributes the highest weights to those national indicators that exhibit the highest degree of forecast accuracy.

Table 3: Area-wide ADL-models using single national indicators as predictors

\begin{tabular}{lccc}
\hline \hline National Indicator Series & IPI & ESI & WES \\
\cline { 2 - 4 } & \multicolumn{3}{c}{ MSE ratio } \\
\hline Austria & 1.63 & - & 1.04 \\
Belgium & 1.34 & 1.42 & 1.27 \\
Finland & 1.75 & 1.35 & 1.69 \\
France & 1.59 & 1.55 & 1.27 \\
Germany & 2.11 & $\mathbf{0 . 5 9}$ & $\mathbf{0 . 7 3}$ \\
Italy & $\mathbf{1 . 1 1}$ & 1.61 & 1.70 \\
Netherlands & 1.70 & 0.84 & 1.23 \\
Portugal & 2.06 & 1.56 & 1.56 \\
Spain & 1.32 & 2.26 & 1.45 \\
\hline \hline
\end{tabular}

Notes: The MSE ratios are calculated as the MSE resulting from national indicators relative to the MSE resulting from economically weighted area-wide indicators. MSE ratios in bold label the best performing nation indicators.

Apart from looking one-dimensionally at the mean forecast error, the theory of portfolio optimization highlights the role of correlations for the determination of the optimal weighting scheme. An analysis of the correlations of the forecast errors resulting from area-wide models that only use a single national indicator as predictor, might in particular be helpful in explaining why some of the rather poorly-performing national indicator series enter the optimally pooled indicators in addition to the best performing national indicators. Table 4 reveals that the optimization algorithm attributes a weight larger than zero to those national indicator series whose forecast errors are only little correlated with the bestperforming national indicators. Consider the Dutch and the Portuguese WES indicators as an example. Although they perform rather poorly when it comes to forecasting euro area real GDP growth - i.e. their MSE ratios are greater than the MSE ratio for the Austrian indicator - they obtain a weight that is far greater than the relative economic share of their economies in the euro area, simply because the correlation between their forecast errors and those resulting 
Table 4: Correlations of forecast errors of the area-wide models using single national indicators as predictors

\begin{tabular}{|c|c|c|c|c|c|c|c|c|c|}
\hline IPI & Aus & Bel & Fin & Fra & Ger & Ita & Net & Por & Spa \\
\hline Aus & 1.00 & 0.68 & 0.84 & 0.76 & 0.46 & 0.81 & 0.71 & 0.86 & 0.87 \\
\hline Bel & 0.68 & 1.00 & 0.68 & 0.58 & 0.53 & 0.74 & 0.60 & 0.66 & 0.70 \\
\hline Fin & 0.84 & 0.68 & 1.00 & 0.74 & 0.36 & 0.79 & 0.63 & 0.82 & 0.83 \\
\hline Fra & 0.76 & 0.58 & 0.74 & 1.00 & 0.57 & 0.75 & 0.75 & 0.87 & 0.82 \\
\hline Ger & 0.46 & 0.53 & 0.36 & 0.57 & 1.00 & 0.59 & 0.50 & 0.58 & 0.58 \\
\hline Ita & 0.81 & 0.74 & 0.79 & 0.75 & 0.59 & 1.00 & 0.81 & 0.93 & 0.88 \\
\hline Net & 0.71 & 0.60 & 0.63 & 0.75 & 0.50 & 0.81 & 1.00 & 0.78 & 0.76 \\
\hline Por & 0.86 & 0.66 & 0.82 & 0.87 & 0.58 & 0.93 & 0.78 & 1.00 & 0.91 \\
\hline Spa & 0.87 & 0.70 & 0.83 & 0.82 & 0.58 & 0.88 & 0.76 & 0.91 & 1.00 \\
\hline ESI & Aus & Bel & Fin & Fra & Ger & Ita & Net & Por & Spa \\
\hline Aus & & & & & & & & & \\
\hline Bel & & 1.00 & 0.55 & 0.69 & 0.61 & 0.66 & 0.70 & 0.63 & 0.41 \\
\hline Fin & & 0.55 & 1.00 & 0.83 & 0.58 & 0.82 & 0.60 & 0.70 & 0.79 \\
\hline Fra & & 0.69 & 0.83 & 1.00 & 0.55 & 0.87 & 0.59 & 0.76 & 0.85 \\
\hline Ger & & 0.61 & 0.58 & 0.55 & 1.00 & 0.65 & 0.47 & 0.58 & 0.48 \\
\hline Ita & & 0.66 & 0.82 & 0.87 & 0.65 & 1.00 & 0.71 & 0.78 & 0.85 \\
\hline Net & & 0.70 & 0.60 & 0.59 & 0.47 & 0.71 & 1.00 & 0.70 & 0.53 \\
\hline Por & & 0.63 & 0.70 & 0.76 & 0.58 & 0.78 & 0.70 & 1.00 & 0.77 \\
\hline Spa & & 0.41 & 0.79 & 0.85 & 0.48 & 0.85 & 0.53 & 0.77 & 1.00 \\
\hline WES & Aus & Bel & Fin & Fra & Ger & Ita & Net & Por & Spa \\
\hline Aus & 1.00 & 0.92 & 0.92 & 0.91 & 0.71 & 0.92 & 0.90 & 0.89 & 0.88 \\
\hline Bel & 0.92 & 1.00 & 0.87 & 0.93 & 0.74 & 0.88 & 0.81 & 0.85 & 0.88 \\
\hline Fin & 0.92 & 0.87 & 1.00 & 0.94 & 0.63 & 0.97 & 0.96 & 0.91 & 0.93 \\
\hline Fra & 0.91 & 0.93 & 0.94 & 1.00 & 0.76 & 0.96 & 0.90 & 0.88 & 0.94 \\
\hline Ger & 0.71 & 0.74 & 0.63 & 0.76 & 1.00 & 0.66 & 0.62 & 0.55 & 0.66 \\
\hline Ita & 0.92 & 0.88 & 0.97 & 0.96 & 0.66 & 1.00 & 0.94 & 0.91 & 0.95 \\
\hline Net & 0.90 & 0.81 & 0.96 & 0.90 & 0.62 & 0.94 & 1.00 & 0.86 & 0.87 \\
\hline Por & 0.89 & 0.85 & 0.91 & 0.88 & 0.55 & 0.91 & 0.86 & 1.00 & 0.86 \\
\hline Spa & 0.88 & 0.88 & 0.93 & 0.94 & 0.66 & 0.95 & 0.87 & 0.86 & 1.00 \\
\hline
\end{tabular}

Notes: Figures in bold label the national indicator series that enter the newly constructed area-wide indicators. 
from the forecasting model using the German indicator as a predictor are among the lowest.

\subsection{Forecast Experiment Using Ex-Post Information}

The critical point of the optimal pooling of information approach is the use of the out-of-sample MSE as the target function of the optimization algorithm since this requires to rely on ex-ante information. By exploiting information stemming from the forecast evaluation window, the approach is advantaged compared to competing forecasting methods in a real-time forecast experiment. To overcome this drawback it has to be shown that the optimal weights reported in Table 2 remain stable over time. In this context stability means that the weights attributed to each national indicator series are robust against variations of the length and the initial date of the optimization window.

In the following we derive optimal weights by focusing on shorter optimization windows that are strictly separated from the evaluation window. Figure 2 presents an overview of the timing of events. Table 5 shows the optimal weights that are computed from rolling fixed length optimization windows with 10 and 15 forecast errors. Given that the number of potential out-of-sample forecasts in the experiment is equal to $\Theta_{2}-\Theta_{0}=27$, we end up with 18 and 13 fixed-length optimization windows, which can be used to derive the weights. A comparison of Table 5 with Table 2 shows that the mean of the weights is similar to the weights computed from the complete optimization window and the variation, measured in terms of standard deviations, decreases with an increasing optimization window. Apparently, the weights are relatively stable which implies that the approach is practical in real time.

Although economic weights pose the most popular aggregation scheme, a number of alternative benchmark models are at disposal. In order to take our optimal pooling approach to a tougher test we compare its forecast accuracy in the following with the competing economic and econometric weighting schemes and prediction approaches presented in Section 2 in a real-time experiment. In addition, we also derive forecasts from an univariate forecast model. The competing forecast models are thereby estimated using the same area-wide and national 
Table 5: Optimal weighting schemes derived from rolling optimization windows with 10 and 15 forecast errors

\begin{tabular}{lccc|ccc}
\hline \hline & \multicolumn{3}{c}{ window size 10 } & \multicolumn{3}{c}{ window size 15 } \\
& IPI & ESI & WES & IPI & ESI & WES \\
\hline Aus & 0.03 & - & 0.00 & 0.00 & - & 0.00 \\
& $(0.04)$ & & $(0.00)$ & $(0.00)$ & & $(0.00)$ \\
Bel & 0.15 & 0.03 & 0.03 & 0.15 & 0.04 & 0.00 \\
& $(0.13)$ & $(0.09)$ & $(0.07)$ & $(0.05)$ & $(0.09)$ & $(0.00)$ \\
Fin & 0.03 & 0.01 & 0.00 & 0.03 & 0.05 & 0.00 \\
& $(0.04)$ & $(0.04)$ & $(0.00)$ & $(0.03)$ & $(0.09)$ & $(0.00)$ \\
Fra & 0.17 & 0.05 & 0.00 & 0.26 & 0.01 & 0.00 \\
& $(0.13)$ & $(0.07)$ & $(0.00)$ & $(0.12)$ & $(0.02)$ & $(0.00)$ \\
Ger & 0.17 & 0.51 & 0.45 & 0.10 & 0.50 & 0.44 \\
& $(0.09)$ & $(0.29)$ & $(0.26)$ & $(0.09)$ & $(0.13)$ & $(0.16)$ \\
Ita & 0.26 & 0.02 & 0.00 & 0.34 & 0.00 & 0.00 \\
& $(0.10)$ & $(0.03)$ & $(0.00)$ & $(0.06)$ & $(0.00)$ & $(0.00)$ \\
Net & 0.12 & 0.15 & 0.19 & 0.09 & 0.24 & 0.27 \\
& $(0.08)$ & $(0.16)$ & $(0.09)$ & $(0.04)$ & $(0.14)$ & $(0.08)$ \\
Por & 0.02 & 0.17 & 0.26 & 0.00 & 0.14 & 0.24 \\
& $(0.03)$ & $(0.22)$ & $(0.22)$ & $(0.01)$ & $(0.14)$ & $(0.16)$ \\
Spa & 0.05 & 0.07 & 0.07 & 0.02 & 0.03 & 0.05 \\
& $(0.09)$ & $(0.18)$ & $(0.06)$ & $(0.04)$ & $(0.05)$ & $(0.04)$ \\
\hline \hline
\end{tabular}

Notes: The Table shows the mean of 18 and 13 optimal weights derived from rolling optimization windows with 10 and 15 forecast errors. The figures in parentheses denote the standard deviations around the mean.

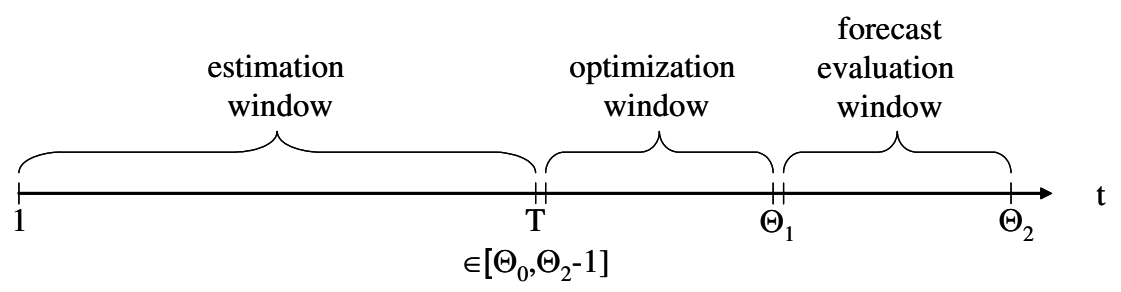

Figure 2: Time structure of the estimation and forecasting procedures 
business cycle indicators at disposal. The optimized weights are derived from a recursively growing optimization window, which is excluded from the forecast evaluation process. ${ }^{11}$ For the first iteration, the optimized indicator is calculated by minimizing the sum of the first 10 out-of-sample squared forecast errors and the forecast of euro area real GDP growth for second quarter 2002 is generated. At each iteration, the optimization window is expanded one quarter and the weights are updated using this recursive approach. The same setting is used to derive the weights for the optimal pooling of area-wide forecasts as described in Section 2.1.1 in detail. Again, the weighting scheme is solely based on ex-post information. Furthermore, at each iteration a static factor model as well as a dynamic factor model are employed to extract an area-wide indicator which is used to forecast current quarter's real GDP growth for the euro area. The area-wide indicator thereby corresponds to the first common factor extracted. ${ }^{12}$ For the aggregation of national GDP forecasts, we employ economic weights based on the relative nominal GDP within the euro area.

Table 6 reports the forecast MSE of the optimal pooling of information approach relative to those of the alternative forecast approaches. The results can be summarized as follows: 1) The optimal pooling of information approach results in general in a lower forecast error, i.e. the MSE ratios are below unity. Only in two cases - for the IPI and the WES - the MSE ratios are above unity. 2) The optimal pooling of information approach outperforms the economic weighting schemes for all three indicators under consideration, which confirms the results obtained in Section 4.3 where we allowed for the use of ex-ante information. However, the improvement is significant only in the cases of the WES and the ESI. Likewise, the optimal pooling of information approach dominates the univariate forecast model significantly in all cases. 3) The HLN test shows at the $10 \%$ significance level that the optimal pooling of information approach significantly dominates 5 of the competing forecast approaches in the case of the IPI and the ESI, and 4

\footnotetext{
${ }^{11}$ Note that we use the first estimate of real GDP growth as the realization to calculate the loss function that is minimized to generate the optimized weights. As before the forecast evaluation is based on real GDP reported one year after the forecast is derived.

${ }^{12}$ The number of common factors extracted as well as the lag-window size used in the dynamic factor model are optimized regarding the ex-post forecast performance of the resulting areawide indicator.
} 
Table 6: Forecast performance of optimal pooling of information relative to traditional forecast strategies

\begin{tabular}{|c|c|c|c|}
\hline & & $\begin{array}{l}\text { MSE } \\
\text { ratio }\end{array}$ & $\begin{array}{c}\text { HLN } \\
\mathrm{p}-\text {-value }\end{array}$ \\
\hline \multirow[t]{10}{*}{$I P I$} & Univariate approach & 0.61 & 0.03 \\
\hline & Pooling of information & & \\
\hline & Economic weights & 0.95 & 0.38 \\
\hline & OLS weights & 0.37 & 0.03 \\
\hline & Principal component analysis & 1.12 & 0.82 \\
\hline & Dynamic factor model & 0.67 & 0.09 \\
\hline & Pooling of forecasts & & \\
\hline & Optimal weighting of area-wide forecasts & 0.74 & 0.07 \\
\hline & Equal weighting of area-wide forecasts & 0.82 & 0.13 \\
\hline & Aggregation of national forecasts & 0.92 & 0.36 \\
\hline \multirow[t]{10}{*}{$E S I$} & Univariate approach & 0.44 & 0.03 \\
\hline & Pooling of information & & \\
\hline & Economic weights & 0.63 & 0.04 \\
\hline & OLS weights & 0.66 & 0.14 \\
\hline & Principal component analysis & 0.67 & 0.05 \\
\hline & Dynamic factor model & 0.89 & 0.33 \\
\hline & Pooling of forecasts & & \\
\hline & Optimal weighting of area-wide forecasts & 0.90 & 0.16 \\
\hline & Equal weighting of area-wide forecasts & 0.65 & 0.07 \\
\hline & Aggregation of national forecasts & 0.70 & 0.11 \\
\hline \multirow[t]{10}{*}{$W E S$} & Univariate approach & 0.48 & 0.06 \\
\hline & Pooling of information & & \\
\hline & Economic weights & 0.64 & 0.03 \\
\hline & OLS weights & 1.11 & 0.60 \\
\hline & Principal component analysis & 0.60 & 0.01 \\
\hline & Dynamic factor model & 0.71 & 0.07 \\
\hline & Pooling of forecasts & & \\
\hline & Optimal weighting of area-wide forecasts & 0.91 & 0.30 \\
\hline & Equal weighting of area-wide forecasts & 0.60 & 0.08 \\
\hline & Aggregation of national forecasts & 0.71 & 0.13 \\
\hline
\end{tabular}

Notes: The MSE ratios are calculated as the MSE resulting from the optimal pooling of information approach relative to the MSE resulting from respective forecast strategy. The HLN p-value was calculated from a Student's $t$-distribution with $\Theta_{2}-\Theta_{0}-1=16$ degrees of freedom. 
of the competing forecast approaches in the case of the WES. 4) In those cases where the MSE ratio is above unity, the optimal pooling of information approach is not systematically beaten by the competing forecast method.

\section{Conclusion}

This paper proposes a new method of forecasting euro area quarterly real GDP that uses area-wide indicators, which are derived by optimally pooling the information contained in national indicator series. Following the ideas of predictive modeling, the area-wide indicators are computed by applying weights that minimize the variance of the out-of-sample forecast error of the aggregate target variable. We evaluate the forecast performance of our optimal pooling of information approach by focusing on three business cycle indicators, namely the Industrial Production Index (IPI), the economic sentiment indicator (ESI) of the European Commission and the CESifo World Economic Survey (WES) indicator for the euro area, which are all available at the area-wide and country-specific level.

Our results show that short-term forecasts of euro area quarterly real GDP are improved by using area-wide indicators based on optimal weights rather than economic weights. The optimally pooled area-wide indicators reduce the out-ofsample MSE by $40 \%$ on average. We also demonstrate that the optimal weights are (1) relatively stable over time and (2) robust against changes in the length of the optimization window, which promotes the practicability of our approach in real-time.

In an out-of-sample forecast experiment we compare the forecast performance of the optimal pooling of information approach with that of a number of competing forecasting strategies. The optimally pooled area-wide indicators are constructed using only information that would have been available in real-time. We find that our method of forecasting performs outperforms competing forecasting methods in terms of forecast accuracy. 


\section{References}

Banerjee, A., M. Marcellino, and I. Masten (2005): "Leading Indicators for Euro-area Inflation and GDP Growth," Oxford Bulletin of Economics \& Statistics, 67(1), 785-813.

BATChELOR, R. (2001): "How Useful are the Forecasts of Intergovernmental Agencies? The IMF and OECD versus the Consensus," Applied Economics, $33(2), 225-235$.

Bates, J., and C. W. J. Granger (1969): "The Combination of Forecasts," Operations Research Quarterly, 20(4), 451-468.

Brodie, J., I. Daubechies, C. De Mol, and D. Giannone (2007): "Sparse and Stable Markowitz Portfolios," CEPR Discussion Papers 6474.

Diebold, F. X., And J. A. Lopez (1996): "Forecast Evaluation and Combination," in Handbook of Statistics, ed. by G. S. Maddala, and C. R. Rao, vol. 14, pp. 241-268. Kluwer Academic Publishers.

Domenico, G., L. Reichlin, and D. Small (2006): "Nowcasting GDP and Inflation: The Realtime Informational Content of Macroeconomic Data Releases," ECB Working Paper Series 633.

European Commission (2007): "The Joint Harmonised EU Programme of Business and Consumer Surveys: User Guide," Economic studies and research, European Commission.

Eurostat (2006): "Methodology of Short-term Statistics: Interpretation and Guidelines," Methods and nomenclatures, Eurostat.

Forni, M., M. Hallin, M. Lippi, And L. Reichlin (2000): "The Generalized Dynamic-Factor Model: Identification and Estimation," The Review of Economics and Statistics, 82(4), 540-554.

Granger, C. W. J., and R. Ramanathan (1984): "Improved Methods for Combining Forecasts," Journal of Forecasting, 3(2), 197-204. 
Harvey, D., S. Leybourne, and P. Newbold (1997): "Testing the Equality of Prediction Mean Squared Errors," International Journal of Forecasting, $13(2), 281-291$.

Kapetanios, G., and M. Marcellino (2006): "A Parametric Estimation Method for Dynamic Factor Models of Large Dimensions," CEPR Discussion Papers 5620.

LütкePohl, H. (1987): Forecasting Aggregated Vector ARMA Processes. Springer Verlag.

Marcellino, M., J. Stock, and M. Watson (2003): "Macroeconomic Forecasting in the Euro Area: Country Specific versus Area-Wide Information," European Economic Review, 47(1), 1-18.

Stangl, A. (2007): "World Economic Survey," in Handbook Of Survey-Based Business Cycle Analysis, ed. by G. Goldrian, pp. 57-67. Ifo Economic Policy Series, Edward Elgar.

Stock, J., And M. Watson (2002): "Macroeconomic Forecasting Using Diffusion Indexes," Journal of Business and Economic Statistics, 20(2), 147-62.

(2004): "Combination Forecasts of Output Growth in a Seven-country Data Set," Journal of Forecasting, 23(6), 405-430.

Timmermann, A. (2005): "Forecast Combinations," in Handbook of Economic Forecasting, ed. by G. C. W. J. Elliott, G., and A. Timmermann. North Holland.

Zarnowitz, V., and P. Braun (1992): "Twenty-Two Years of the NBERASA Quarterly Outlook Surveys: Aspects and Comparisons of Forecast Performance," NBER Working Papers 3965. 


\section{CESifo Working Paper Series}

for full list see www.cesifo-group.org/wp

(address: Poschingerstr. 5, 81679 Munich, Germany, office@cesifo.de)

2309 Peter Egger and Doina Maria Radulescu, Labour Taxation and Foreign Direct Investment, May 2008

2310 Laurent Linnemer, Dissipative Advertising Signals Quality even without Repeat Purchases, May 2008

2311 Jordi Jofre-Monseny and Albert Solé-Ollé, Which Communities should be afraid of Mobility? The Effects of Agglomeration Economies on the Sensitivity of Firm Location to Local Taxes, May 2008

2312 Andreas Haufler and Ferdinand Mittermaier, Unionisation Triggers Tax Incentives to Attract Foreign Direct Investment, May 2008

2313 Ronel Elul and Piero Gottardi, Bankruptcy: Is it enough to Forgive or must we also Forget?, May 2008

2314 Andreas Irmen and Johanna Kuehnel, Productive Government Expenditure and Economic Growth, May 2008

2315 Beate Henschel, Carsten Pohl and Marcel Thum, Demographic Change and Regional Labour Markets: The Case of Eastern Germany, May 2008

2316 Gabriel Felbermayr, Wido Geis and Wilhelm Kohler, Restrictive Immigration Policy in Germany: Pains and Gains Foregone?, May 2008

2317 Michael Hofmann, Gerhard Kempkes and Helmut Seitz, Demographic Change and Public Sector Budgets in a Federal System, May 2008

2318 Paul De Grauwe, Macroeconomic Modeling when Agents are Imperfectly Informed, June 2008

2319 Johann K. Brunner and Susanne Pech, Optimum Taxation of Inheritances, June 2008

2320 Thomas Eichner and Marco Runkel, Corporate Income Taxation of Multinationals in a General Equilibrium Model, June 2008

2321 Rainald Borck and Matthias Wrede, Subsidies for Intracity and Intercity Commuting, June 2008

2322 Patricia Apps and Ray Rees, Testing the Pareto Efficiency of Household Resource Allocations, June 2008

2323 Amihai Glazer, Vesa Kanniainen and Panu Poutvaara, Firms' Ethics, Consumer Boycotts, and Signalling, June 2008 
2324 Claudia M. Buch, Jörg Döpke and Kerstin Stahn, Great Moderation at the Firm Level? Unconditional vs. Conditional Output Volatility, June 2008

2325 Helmuth Cremer, Philippe De Donder, Dario Maldonado and Pierre Pestieau, Forced Saving, Redistribution and Nonlinear Social Security Schemes, June 2008

2326 M. Hashem Pesaran and Paolo Zaffaroni, Optimal Asset Allocation with Factor Models for Large Portfolios, June 2008

2327 Harald Badinger and Peter Egger, Horizontal versus Vertical Interdependence in Multinational Activity, June 2008

2328 Jan K. Brueckner and Harris Selod, A Theory of Urban Squatting and Land-Tenure Formalization in Developing Countries, June 2008

2329 Paolo M. Panteghini, Corporate Debt, Hybrid Securities and the Effective Tax Rate, June 2008

2330 Guglielmo Maria Caporale, Juncal Cuñado and Luis A. Gil-Alana, Modelling Long-Run Trends and Cycles in Financial Time Series Data, June 2008

2331 Avi Ben-Bassat and Momi Dahan, Social Identity and Voter Turnout, June 2008

2332 Martin R. West and Ludger Wößmann, "Every Catholic Child in a Catholic School”: Historical Resistance to State Schooling, Contemporary Private Competition, and Student Achievement across Countries, June 2008

2333 Erkki Koskela and Panu Poutvaara, Outsourcing and Labor Taxation in Dual Labor Markets, June 2008

2334 Philippe Choné and Laurent Linnemer, Optimal Litigation Strategies with Signaling and Screening, June 2008

2335 Albert Solé-Ollé and Pilar Sorribas-Navarro, Does Partisan Alignment Affect the Electoral Reward of Intergovernmental Transfers?, June 2008

2336 Antonio Cabrales and Piero Gottardi, Markets for Information: Of Inefficient Firewalls and Efficient Monopolies, June 2008

2337 Sumon Majumdar and Sharun W. Mukand, The Leader as Catalyst - on Leadership and the Mechanics of Institutional Change, June 2008

2338 Ulrich Hange, Tax Competition, Elastic Labor Supply, and Growth, June 2008

2339 Guy Laroque and Bernard Salanié, Does Fertility Respond to Financial Incentives?, June 2008

2340 Adriano Paggiaro, Enrico Rettore and Ugo Trivellato, The Effect of Extending the Duration of Eligibility in an Italian Labour Market Programme for Dismissed Workers, June 2008 
2341 Helmut Seitz, Minimum Standards, Fixed Costs and Taxing Autonomy of Subnational Governments, June 2008

2342 Robert S. Chirinko, Leo de Haan and Elmer Sterken, Asset Price Shocks, Real Expenditures, and Financial Structure: A Multi-Country Analysis, July 2008

2343 Wolfgang Leininger, Evolutionarily Stable Preferences in Contests, July 2008

2344 Hartmut Egger and Udo Kreickemeier, Fairness, Trade, and Inequality, July 2008

2345 Ngo Van Long and Bodhisattva Sengupta, Yardstick Competition, Corruption, and Electoral Incentives, July 2008

2346 Florian Baumann, Employment Protection: The Case of Limited Enforceability, July 2008

2347 Alessandro Balestrino, Cinzia Ciardi and Claudio Mammini, On the Causes and Consequences of Divorce, July 2008

2348 Dirk Schindler and Benjamin Weigert, Insuring Educational Risk: Opportunities versus Income, July 2008

2349 Lammertjan Dam and Ben J. Heijdra, The Environmental and Macroeconomic Effects of Socially Responsible Investment, July 2008

2350 Avner Greif, Contract Enforcement and Institutions among the Maghribi Traders: Refuting Edwards and Ogilvie, July 2008

2351 Helmuth Cremer, Philippe De Donder, Dario Maldonado and Pierre Pestieau, Habit Formation and Labor Supply, July 2008

2352 Francesco Menoncin and Paolo M. Panteghini, The Johansson-Samuelson Theorem in General Equilibrium: A Rebuttal, July 2008

2353 Michael Kaganovich and Itzhak Zilcha, Alternative Social Security Systems and Growth, July 2008

2354 Keith Blackburn, Kyriakos C. Neanidis and M. Emranul Haque, Corruption, Seigniorage and Growth: Theory and Evidence, July 2008

2355 Edward Castronova, A Test of the Law of Demand in a Virtual World: Exploring the Petri Dish Approach to Social Science, July 2008

2356 Harald Badinger and Peter Egger, GM Estimation of Higher-Order Spatial Autoregressive Processes in Cross-Section Models with Heteroskedastic Disturbances, July 2008

2357 Wolfgang Buchholz and Jan Schumacher, Discounting the Long-Distant Future: A Simple Explanation for the Weitzman-Gollier-Puzzle, July 2008 
2358 Luca Anderlini, Leonardo Felli and Alessandro Riboni, Statute Law or Case Law?, July 2008

2359 Guglielmo Maria Caporale, Davide Ciferri and Alessandro Girardi, Are the Baltic Countries Ready to Adopt the Euro? A Generalised Purchasing Power Parity Approach, July 2008

2360 Erkki Koskela and Ronnie Schöb, Outsourcing of Unionized Firms and the Impacts of Labour Market Policy Reforms, July 2008

2361 Francisco Alvarez-Cuadrado and Ngo Van Long, A Permanent Income Version of the Relative Income Hypothesis, July 2008

2362 Gabrielle Demange, Robert Fenge and Silke Uebelmesser, Financing Higher Education and Labor Mobility, July 2008

2363 Alessandra Casarico and Alessandro Sommacal, Labor Income Taxation, Human Capital and Growth: The Role of Child Care, August 2008

2364 Antonis Adam, Manthos D. Delis and Pantelis Kammas, Fiscal Decentralization and Public Sector Efficiency: Evidence from OECD Countries, August 2008

2365 Stefan Voigt, The (Economic) Effects of Lay Participation in Courts - A Cross-Country Analysis, August 2008

2366 Tobias König and Andreas Wagener, (Post-)Materialist Attitudes and the Mix of Capital and Labour Taxation, August 2008

2367 Ximing Wu, Andreas Savvides and Thanasis Stengos, The Global Joint Distribution of Income and Health, August 2008

2368 Alejandro Donado and Klaus Wälde, Trade Unions Go Global!, August 2008

2369 Hans Gersbach and Hans Haller, Exit and Power in General Equilibrium, August 2008

2370 Jan P.A.M. Jacobs and Jan-Egbert Sturm, The Information Content of KOF Indicators on Swiss Current Account Data Revisions, August 2008

2371 Oliver Hülsewig, Johannes Mayr and Timo Wollmershäuser, Forecasting Euro Area Real GDP: Optimal Pooling of Information, August 2008 